\title{
Article \\ Optimal Control for a Hydraulic Recuperation System Using Endoreversible Thermodynamics
}

\author{
Robin Masser and Karl Heinz Hoffmann *
}

check for

updates

Citation: Masser, R.; Hoffmann, K.H. Optimal Control for a Hydraulic

Recuperation System Using

Endoreversible Thermodynamics.

Appl. Sci. 2021, 11, 5001. https://

doi.org/10.3390/app11115001

Academic Editors: Antonio

Soria-Verdugo, Ignacio

López-Paniagua and Javier

Rodríguez-Martín

Received: 19 April 2021

Accepted: 24 May 2021

Published: 28 May 2021

Publisher's Note: MDPI stays neutral with regard to jurisdictional claims in published maps and institutional affiliations.

Copyright: (c) 2021 by the authors. Licensee MDPI, Basel, Switzerland. This article is an open access article distributed under the terms and conditions of the Creative Commons Attribution (CC BY) license (https:// creativecommons.org/licenses/by/ $4.0 /)$.
Institut für Physik, Technische Universität Chemnitz, 09107 Chemnitz, Germany; robin.masser@physik.tu-chemnitz.de

* Correspondence: hoffmann@physik.tu-chemnitz.de; Tel.: +49-371-531-219-50
Keywords: non-equilibrium thermodynamics; endoreversible thermodynamics; energy recovery; hydraulic hybrid; optimization; optimal control; sustainability

\section{Introduction}

For achieving the global goal of reduced fossil fuel consumption and $\mathrm{CO}_{2}$ emissions the automotive sector plays an important role. In particular, energy recovery systemselectrical, mechanical or hydraulic-are an effective approach to use otherwise wasted energy and improve the vehicles overall efficiency [1-9]. The starting point of this work is a research project that focuses on hydraulic recuperation systems for medium and heavy commercial vehicles with tipper bodies. For these the use of a hydraulic system for mechanical energy recuperation is particularly promising since these vehicles already have a hydraulic system propelling the tipping body. If this system is complemented by a hydraulic accumulator with its particularly high energy and power density, it is able to absorb high energy fluxes when braking. Then the brake energy, which is absorbed using a hydraulic unit mounted on the cardan shaft, can be stored in the hydraulic accumulator. This not only allows to reuse the energy stored to accelerate the vehicle as well as to operate the auxiliary units, but it also reduces the wear of the conventional disc brakes.

When investigating and optimizing hydraulic systems, a comprehensive thermodynamic description is necessary to take thermodynamic effects of the fluid movements and heat transfers into account [10]. Therefore, we introduce a model that is build using endoreversible thermodynamics - an approach based on dividing the system in question into reversible acting subsystems and incorporating reversible or irreversible interactions between them [11]. During the last decades, this method has been used for modeling a variety of technical and natural systems such as heat engines [12-18], thermoelectric refrigerators [19,20], electrochemical devices [21,22] and solar thermal heat engines [23-27]. Even chemical reactions [28,29], global wind energy production [30] and computation [31] have been modeled and investigated using endoreversible thermodynamics. Control or trajectory optimizations have been carried out, too, e.g., for piston movements of Otto [32,33], 
Diesel [34,35], Miller [36] and Brayton [37,38] and Stirling [39] cycles as well as light-driven engines [40-42]. These investigations all show, that it is important to put the focus on dynamical features [43] in order to reach the desired efficiency improvements. This is in particular true for systems in which some of the important input variables to the system are fluctuating. Very recently, the first steps in that regard have been taken in the analysis of stochastic heat engines [44-46].

Based on a comprehensive endoreversible model and realistic input data for driving profiles optimal control strategies can be developed such that the recuperation system achieves significant reduction in operating costs.

A simple control strategy would be based on the presumption that the system supports the conventional power train as soon as possible, either by being switched on in parallel or by replacing the propulsion by the combustion engine. This strategy is typically the baseline strategy and thus the reference point to which control optimization approaches are compared to. Publications often aim at deterministic control strategies that support the combustion engine in its low efficiency areas while taking the efficiency map of the hydraulic unit into account [6,47-49]. However, thermodynamic effects such as heat or pressure losses depending on the dynamics of the system are typically neglected.

In this work, the endoreversible modeling includes the internal combustion engine and the transmission to consider not only power sharing and resulting energy savings, but also the efficiency of the engine and thus the resultant reduction of fuel consumption. Using this model and realistic driving data, an optimization of the control strategy will be carried out, and its potential to reduce fuel consumption will be shown.

\section{Hydraulic Recuperation System}

The hydraulic system for mechanical energy recuperation considered here consists of the following components: a hydraulic fluid tank, a hydraulic pump/motor which is mounted to and driven by the vehicle's cardan shaft, a hydraulic bladder accumulator and the pipes connecting these components.

The hydraulic pump/motor-or simply hydraulic unit—has the ability to operate both as a pump and as a motor, and with variable displacement. This means that a flow of hydraulic fluid can be generated using the input power from the cardan shaft, or a power output can propel the cardan shaft driven by a fluid flow, respectively. We use a displacement factor $\gamma$ defining the ratio of current displacement to maximum displacement of the hydraulic unit, so that $-1 \leq \gamma \leq 1$ holds, to describe the operation mode. A negative displacement factor means that hydraulic unit acts as a pump.

In this case, the hydraulic fluid is pumped from the low pressure hydraulic fluid tank to the high-pressure bladder accumulator. The inflowing hydraulic fluid within the bladder accumulator compresses the gas leading to a pressure increase. In this way, energy can be stored. The needed work is taken from the cardan shaft which decelerates the vehicle. Another useful effect of this is that the conventional disc brakes are supported and therefore have to absorb less energy resulting in reduced wear.

If a certain amount of hydraulic fluid is within the bladder accumulator and hence there is energy stored within, the hydraulic unit can act as a motor. The high pressure causes a fluid flow in the opposite direction which propels the hydraulic motor mounted to the cardan shaft. The power carried by this fluid flow from a high to a low pressure is transferred to the cardan shaft accelerating the vehicle.

For the detailed description of a comparable recuperation system, which includes also a pressure relief line, the reader is referred to [50].

\section{Endoreversible Thermodynamics}

The endoreversible thermodynamics approach $[11,51]$ is based on two steps: First, the system in question is divided into reversible acting subsystems. Second, reversible or irreversible interactions between these subsystems are incorporated. As a result, irreversibilities are limited to occur in interactions only. 
Subsystems are differentiated depending on whether they can store energy or not into reservoirs or engines, respectively. Reservoirs are further divided into finite and infinite reservoirs. A finite reservoir $i$ is typically described by its energy $E_{i}$ which is a function of its extensive quantities-short extensities. For each extensity $X_{i}^{\alpha}$, there is a corresponding intensive quantity $Y_{i}^{\alpha}$-short intensity. This intensity can be obtained by

$$
Y_{i}^{\alpha}=\frac{\partial E_{i}\left(X_{i}^{\alpha}\right)}{\partial X_{i}^{\alpha}},
$$

where the superscript $\alpha$ is used to define the specific type of extensity. If e.g., $\alpha=S$ then the extensity $X^{S}$ is the entropy $S$ and the corresponding intensity $Y^{S}$ is the temperature $T$.

The energy of the finite reservoir varies with the changes in extensive quantities and energy changes can be calculated as

$$
\mathrm{d} E_{i}=\sum_{\alpha} Y_{i}^{\alpha} \mathrm{d} X_{i}^{\alpha}
$$

Accordingly, each flux of extensity $J_{i}^{\alpha}$ carries an accompanying flux of energy given by

$$
I_{i}=Y_{i}^{\alpha} J_{i}^{\alpha} .
$$

Infinite reservoirs, on the other hand, have a fixed intensity which does not change due to extensity transfers to or from them. Therefore, solely their intensities are used to describe them.

As already indicated, the endoreversible subsystem type engine can neither store energy nor extensities and the balance equations have to be fulfilled at all time:

$$
\begin{aligned}
& 0=\sum_{k} J_{i, k}^{\alpha} \text { for all } \alpha \text { and } \\
& 0=\sum_{k} I_{i, k} .
\end{aligned}
$$

Here, $k$ is used to consecutively number the subsystem's contact points which connect the subsystem $i$ to other subsystems.

The interactions that connect the subsystems with each other are defined either by setting intensities of the connected subsystems equal or by defining a specific transport law. In the first case, the occurring fluxes instantaneously equalize the intensities of the subsystems. In the latter case, typically phenomenological relationships are used.

Interactions can be irreversible and thus generate entropy. All other extensities and of course energy have to be balanced over the interaction. Furthermore, if only the transferred amount of energy is of interest but not the extensive quantities that carry this energy, a simple power flux can be used describing the rate of the energy transfer.

In [11,29], a more comprehensive as well as more detailed description of the endoreversible thermodynamics can be found. Furthermore, we introduced a dissipative engine setup based on a more general interaction type in [52]. Using this dissipative engine setup, engines, for which efficiency or power output data are already given [53] and may be arbitrary functions of any parameters, can easily be modeled and incorporated without loss of accuracy.

\section{Endoreversible Model}

Based on the above described modeling approach we develop an endoreversible model of the mechanical energy recuperation system. A central element of that model is the cardan shaft as the connecting link between recuperation system, combustion engine and brakes. The endoreversible model of the hybrid drive train is shown in Figure 1. 


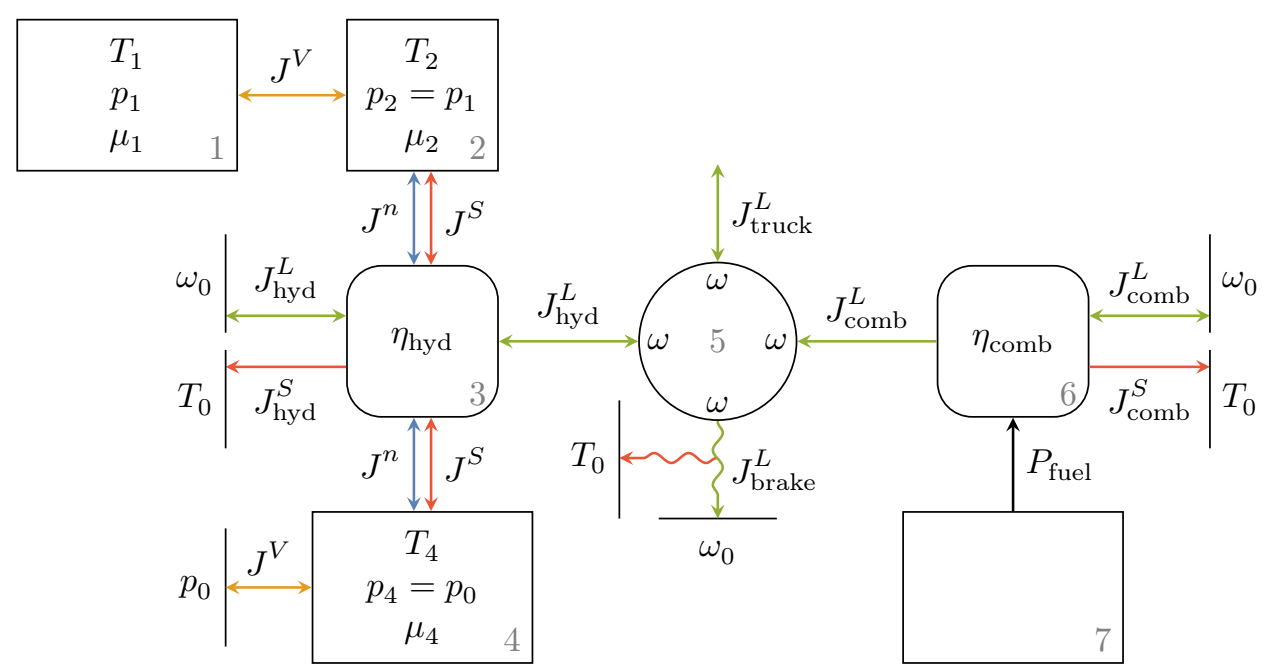

Figure 1. Endoreversible model used for fuel consumption minimization. The recuperation system is represented by the gas 1 and the hydraulic fluid 2 within the bladder accumulator, the hydraulic unit 3 and the hydraulic fluid tank 4. Engine 5 represents the cardan shaft and engine 6 is the combustion engine connected to a work reservoir 7 representing the diesel fuel tank. Energy transfers via the cardan shaft are carried by angular momentum fluxes. The angular momentum flux towards the chassis of the vehicle with angular velocity $\omega_{0}=0$ represents energy dissipation at the conventional disc brakes.

On the left side of the figure we can see the subsystems 1 to 4 , which represent the recuperation system. Here, reservoirs 1 and 2 are the gas and the hydraulic fluid within the bladder accumulator, the dissipative engine 3 represents the hydraulic unit, and reservoir 4 represents the hydraulic fluid tank. The hydraulic fluid flow is modeled by a coupled reversible particle and entropy flux $\left(J^{n}\right.$ and $J^{S}$, respectively). Such coupled fluxes can be efficiently treated by a so-called multi-extensity flux [29]. The reversible volume fluxes $\left(J^{V}\right)$ represent the volume exchange at equal pressure between the inside and outside of the accumulator bladder.

In case of the hydraulic unit-the dissipative engine 3-we consider two extensity transfers namely a combined particle and entropy transfer, as well as an angular momentum transfer. Here, the angular momentum flux $J_{\text {hyd }}^{L}$ connects the hydraulic unit with engine 5 which represents the cardan shaft of the vehicle with angular velocity $\omega$. Since the latter is assumed to not store but only transfer energy in a reversible manner, the modeling as a simple endoreversible engine is appropriate. Further, it is connected to the dissipative engine 6 which represents the internal combustion engine. The irreversible angular momentum flux $J_{\text {brake }}^{L}$ towards an infinite reservoir with intensity $\omega_{0}=0$ represents the energy absorption and dissipation at the conventional disc brakes, and a reversible angular momentum flux $J_{\text {truck }}^{L}$ is carrying the transferred energy to accelerate or decelerate the truck. The internal combustion engine is modeled as a dissipative engine with torque output represented by the flux $J_{\text {comb }}^{L}$ and with a power input $P_{\text {fuel }}$ without specified carrying extensity from the work reservoir 7 .

Note that there is actually no direct angular momentum transfer between the cardan shaft and the disc brakes. The cardan shaft transfers the angular momentum of the hydraulic unit and the combustion engine towards the wheels which then transfer angular momentum to the disc brakes when braking. However, the simplified representation here suffices for the modeling.

Having an overview of the model, we begin again from the left side of Figure 1 describing the interactions as well as the gas and the hydraulic fluid within the system. The gas within the bladder accumulator is modeled as a van der Waals gas and there is equilibrated pressure $p_{1}=p_{2}$ and a constant overall volume $V_{\text {acc }}=V_{1}+V_{2}$ within the accumulator-implemented by means of the reversible volume flux $J^{V}$. Hence we can write 


$$
\dot{V}_{1}=J^{V}=-\dot{V}_{2}
$$

for the volume flux between the gas and the hydraulic fluid. The hydraulic fluid is modeled as an incompressible liquid, which is a suitable assumption for liquids in general.

A fluid flow described by a combined particle and entropy flux can also be described as an enthalpy flux and thus

$$
J^{n}\left(\mu+T S_{m}\right)=J^{n}\left(U_{m}+p V_{m}\right)
$$

holds, where $\mu$ is the chemical potential and $S_{m}, U_{m}$, and $V_{m}$ are the molar entropy, the molar internal energy and the molar volume of the fluid, respectively. Using this, the volume change of reservoir 2 can simply be expressed as

$$
\dot{V}_{2}=J^{n} V_{m}
$$

with the particle flux $J^{n}$ towards engine 3.

As far as the hydraulic unit is concerned, we use the overall efficiency of the hydraulic unit

$$
\eta_{\text {hyd }}=\eta_{\text {mech }}\left(\gamma, n_{\text {cyc }}\right) \eta_{\text {vol }}\left(\gamma, n_{\text {cyc }}\right),
$$

where the mechanical and volumetric efficiencies, $\eta_{\text {mech }}$ and $\eta_{\mathrm{vol}}$, respectively, are functions of the displacement factor of the hydraulic unit $\gamma$ (see Equation (15)), the rotational speed of the cardan shaft $n_{\text {cyc }}=\omega / 2 \pi$ and the pressure difference $\Delta p=p_{2}-p_{4}$. For $\eta_{\text {mech }}$ and $\eta_{\mathrm{vol}}$ we use polynomial fits of measured data from a radial piston pump which are shown in [50]. The overall efficiency of the hydraulic unit $\eta_{\text {hyd }}$ determines a loss flux of angular momentum and the corresponding generated entropy which is transferred to the environment.

In case of the hydraulic unit acting as a pump, according to the description of the dissipative engine with given efficiency [52], the loss angular momentum and entropy flux can be written as

$$
\begin{aligned}
J_{\text {hyd,loss }}^{L} & =J_{\text {hyd }}^{L}\left(\frac{1}{\eta_{\text {mech }}} \frac{p_{2}}{p_{2}-p_{4}}-1\right), \\
J_{\text {hyd }}^{S} & =J_{\text {loss,hyd }}^{L} \frac{\omega}{T_{0}}
\end{aligned}
$$

where we inserted the angular velocity $\omega_{0}=0$ of the vehicle's chassis, to which $J_{\text {loss,hyd }}^{L}$ is transferred. In Figure 1, this flux is a portion of the flux $J_{\text {hyd }}^{L}$ towards the reservoir with $\omega_{0}$, while the other portion is the excess angular momentum resulting from the angular momentum balance of the hydraulic unit. Assuming $T_{2}=T_{4}$ so that $U_{m, 2}=U_{m, 4}$, we can thus write

$$
\begin{aligned}
0 & =J_{\text {hyd }}^{L} \omega+J_{\text {hyd }}^{S} T_{0}+J^{n}\left(p_{2}-p_{4}\right) V_{m} \\
& =J_{\text {hyd }}^{L} \omega \eta_{\text {hyd }}+J^{n}\left(p_{2}-p_{4}\right) V_{m}
\end{aligned}
$$

where we used Equation (7).

The same procedure can be done for the hydraulic unit in motor mode and we obtain

$$
0=J_{\text {hyd }}^{L} \omega+\eta_{\text {hyd }} J^{n}\left(p_{2}-p_{4}\right) V_{m}
$$

as the governing equation.

Using the molar volume of the hydraulic fluid the particle flux $J^{n}$ can be calculated as

$$
J^{n}=\frac{\gamma n_{\mathrm{cyc}} V_{\mathrm{d}}}{V_{m}}
$$


for both pump and motor mode. Here, the term above the fraction is the volumetric flow rate through the hydraulic unit with the maximum displacement of the hydraulic unit $V_{\mathrm{d}}$.

We can now define the input or output power of the recuperation system as

$$
P_{\text {rec }}=I_{\text {hyd }}=J_{\text {hyd }}^{L} \omega
$$

for both pump and motor mode, respectively, as well as the braking power towards the conventional disc brakes and the power contributed by the combustion engine as

$$
\begin{aligned}
& P_{\text {brake }}=I_{\text {brake }}=J_{\text {brake }}^{L} \omega, \\
& P_{\text {comb }}=I_{\text {comb }}=J_{\text {comb }}^{L} \omega,
\end{aligned}
$$

respectively. The energy transfer (towards tires and street) that is accelerating the truck is then provided by the recuperation system and the combustion engine so that

$$
P_{\text {truck }}=P_{\text {rec }}+P_{\text {comb }}
$$

holds. Otherwise, if the truck decelerates, that power can be stored in the recuperation system or transferred to the discs brakes where it is dissipated, and hence

$$
P_{\text {truck }}=P_{\text {rec }}+P_{\text {brake }}
$$

Based on a driving profile with velocity $v$ and incline $\alpha$, the power $P_{\text {truck }}$ for this profile can be calculated by

$$
\begin{aligned}
P_{\text {truck }}= & f_{\mathrm{m}} m \frac{\mathrm{d} v}{\mathrm{~d} t} v+m g c_{\mathrm{rr}} \cos (\alpha)|v|+ \\
& \frac{\rho_{\text {air }}}{2} c_{\mathrm{d}} A|v|^{3}+m g \sin (\alpha) v .
\end{aligned}
$$

Here, the four terms represent acceleration, rolling resistance, aerodynamic drag and change in potential energy. The parameters used are the mass factor $f_{\mathrm{m}}$ and mass $m$ of the vehicle, gravitational acceleration $g$ and coefficient of rolling resistance $c_{\mathrm{rr}}$, the density of air $\rho_{\text {air }}$ as well as the drag coefficient $c_{\mathrm{d}}$ and the cross sectional area $A$ of the truck. With the sign convention used, $P_{\text {truck }}$ is positive when the vehicle needs power to accelerate or to maintain its velocity.

The internal combustion engine is also modeled as a dissipative engine with given efficiency but with unspecified power input $P_{\text {fuel }}$ from the work reservoir 7 which represents the fuel tank. For named engine we can simply write

$$
P_{\text {fuel }}=\frac{P_{\text {comb }}}{\eta_{\text {comb }}}
$$

where $P_{\text {fuel }}$ is the power equivalent of the diesel fuel flux. Thus, the actual mass flow of diesel fuel into the combustion engine can be calculated by

$$
\dot{m}_{\text {fuel }}=\frac{P_{\text {fuel }}}{L H V},
$$

where $L H V$ is the lower heating value of diesel fuel.

\section{Combustion Engine and Transmission}

Figure 2 shows a typical brake specific fuel consumption map of a large diesel engine used in a medium heavy truck. Here, the brake specific fuel consumption BSFC which represents the value of current fuel consumption is shown over the mean effective pressure $p_{\mathrm{me}}$ and the rotational speed $n_{\mathrm{cyc}, \mathrm{comb}}$ of the engine. The mean effective pressure is a variable to assess the efficiency of reciprocating engines regardless of the engine size. In 
a four-stroke engine with two revolutions per power stroke, it can be converted into the output torque

$$
\tau_{\mathrm{comb}}=p_{\mathrm{me}} \frac{V_{\mathrm{d}, \mathrm{comb}}}{4 \pi},
$$

where $V_{\mathrm{d}, \mathrm{comb}}$ is the displacement of the combustion engine.

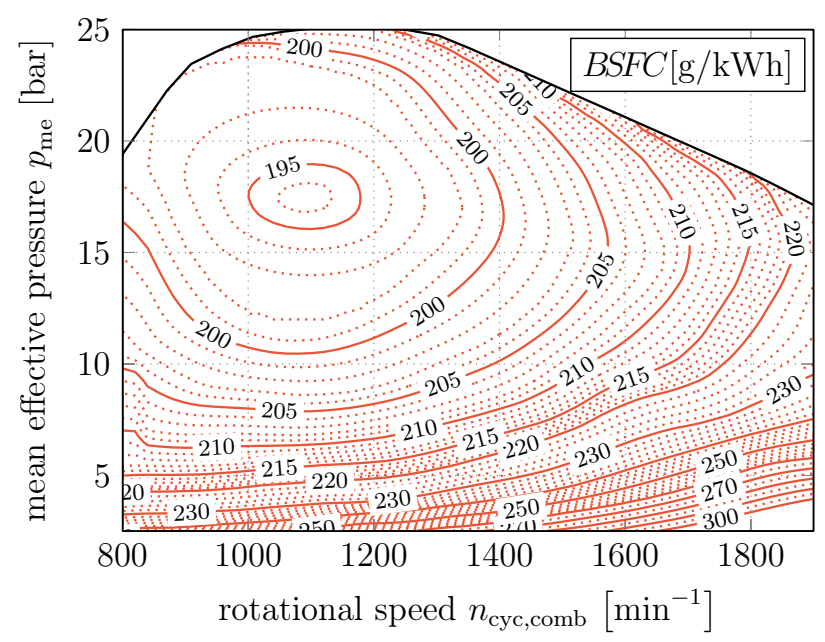

Figure 2. Brake specific fuel consumption map over mean effective pressure and rotational speed of the combustion engine. For this, a typical map for large diesel engines was used and scaled to an actual minimum fuel consumption value of $193 \mathrm{~g} / \mathrm{kWh}$.

However, the rotational speed of the engine is related to that of the cardan shaft only via the transmission and therefore varies with the gear engaged. The same applies to the torque transferred to the cardan shaft $\tau_{\text {card, }}$ while their relations are given by

$$
\begin{aligned}
\tau_{\mathrm{card}} & =R_{\mathrm{t}, i} \tau_{\mathrm{comb}} \\
n_{\mathrm{cyc}} & =\frac{n_{\mathrm{cyc}, \mathrm{comb}}}{R_{\mathrm{t}, i}},
\end{aligned}
$$

respectively, where $R_{\mathrm{t}, i}$ are the gear ratios depending on the selected gear $i$.

We want to avoid the modeling and simulation of the gear shifting and therefore assume that the selected gear always yields the lowest possible BSFC for the desired torque output and rotational speed of the cardan shaft. Using gear ratios of a twelve-speed automatic transmission, we obtain the scheme which is shown in Figure 3. The resulting gear, which is optimal with regard to minimal fuel consumption, is shown as a function of the desired torque output and the vehicle velocity. As expected with a transmission, it can be seen that the low gears transmit high torques at low speeds, and the high gears at high speeds can transmit only little torque. The empty area at high torques and high velocity exceeds the maximum power of the internal combustion engine.

Using this optimal gear scheme, we can now plot the BSFC over the desired power output for different values of the vehicle's velocity as shown in Figure 4. Here, one notices that the jumps caused by gear changes are relatively small. The main dependence is the power output, while for increasing velocity the BSFC can be kept approximately constant by changing gears. Greater deviations from this only occur for high power outputs, which are more likely to occur when driving on highways than in urban areas.

Given that, averaging the $B S F C$ values over speed will yield a sufficiently good approximation. Using the lower heating value of diesel fuel $L H V$ and the averaged values $\overline{B S F C}$ we can calculate the efficiencies of the engine for given power output as

$$
\bar{\eta}_{\mathrm{comb}}=\frac{1}{\overline{B S F C} L H V}
$$


and use a polynomial fit to reproduce the resultant curve as shown in Figure 5. Note that the transmission itself has an efficiency close to 1 , which is therefore not considered here. Furthermore, engine starts or shutdowns are not considered and the engine does not use diesel fuel at idle in this model.

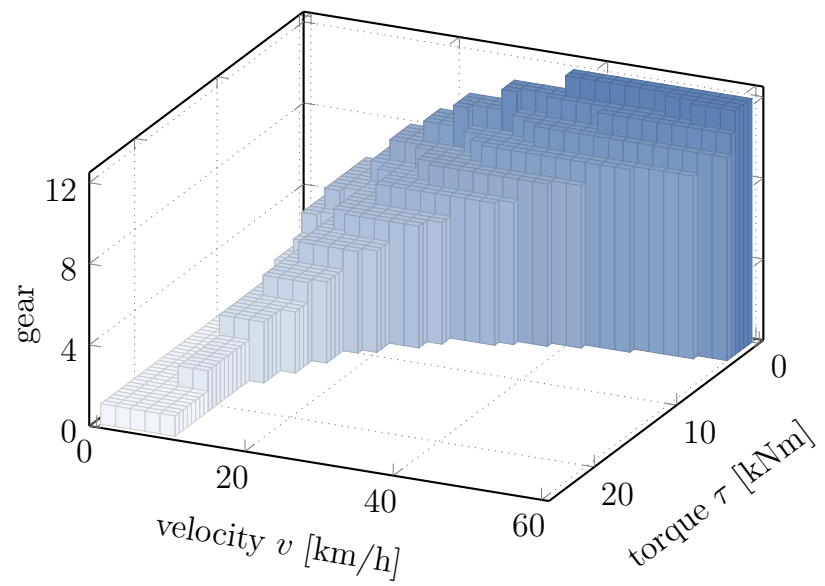

Figure 3. Optimal gears to achieve lowest brake specific fuel consumption over velocity and desired torque output of the combustion engine. The empty area exceeds the engines maximum power output.

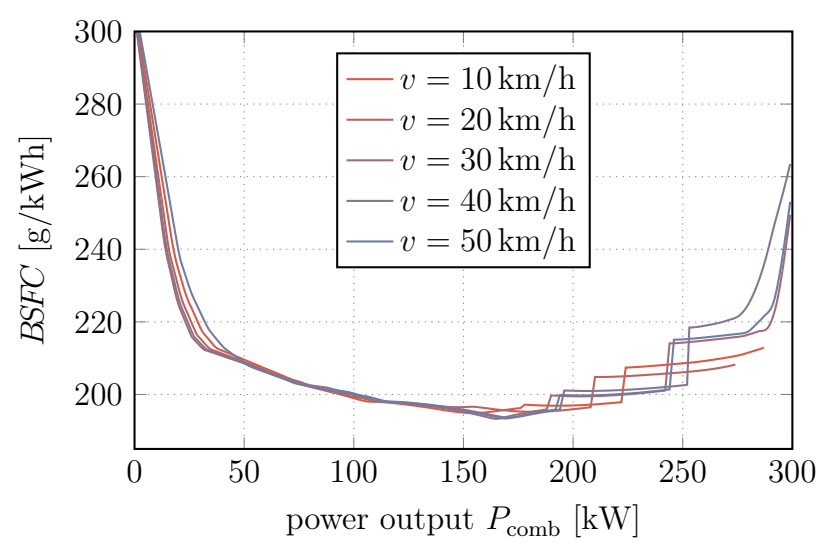

Figure 4. Lowest achievable brake specific fuel consumption using optimal gears (Figure 3) desired power output of the combustion engine.

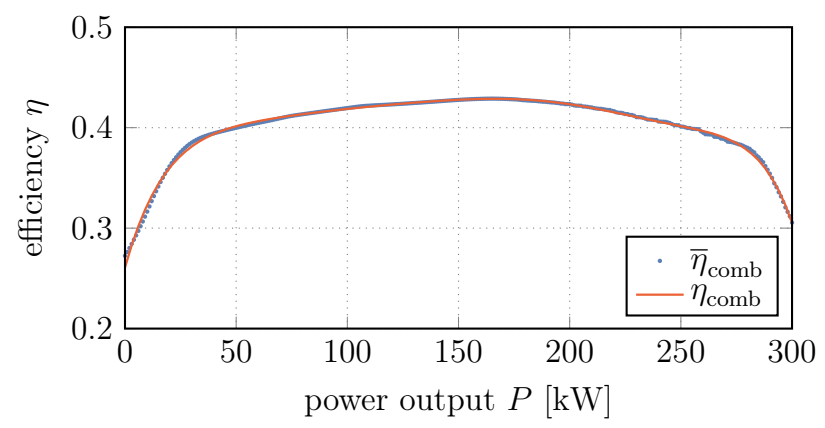

Figure 5. Averaged values (blue dots) and polynomial fit (red line) of combustion engine efficiency over desired power output using optimal gears for lowest brake specific fuel consumption (Figure 3).

\section{Optimization}

The objective function of the optimization is the total work

$$
W=\int_{t_{0}}^{t_{\text {end }}} P_{\text {fuel }} \mathrm{d} t
$$


which the combustion engine receives from the work reservoir 7 . This represents the total diesel fuel consumption for a driving profile over the time interval $t=\left[t_{0}, t_{\text {end }}\right]$ and shall be minimized. The control variable is the displacement factor $\gamma$ which determines the power input and output of the recuperation system. By definition it is constrained by

$$
-1 \leq \gamma \leq 1
$$

Furthermore, we define the pressure of the gas as a state variable, for which the van der Waals equation of state given by

$$
\left(p_{1}+\frac{n_{1}^{2} a}{V_{1}^{2}}\right)\left(V_{1}-n_{1} b\right)=n_{1} R T_{1}
$$

with the van der Waals parameters for nitrogen has to be fulfilled at any time. Additionally, the following conditions apply to ensure reasonable functioning of the recuperation system:

$$
\begin{array}{ll}
V_{1} \leq V_{\text {acc }}-V_{\text {min }} & \\
p_{1} \leq p_{\text {max }}, & \\
P_{\text {truck }} \geq P_{\text {rec }} \geq P_{\text {truck }}-P_{\text {comb,max }} & \text { if } P_{\text {truck }} \geq 0 \text { and } \\
P_{\text {truck }} \leq P_{\text {rec }} \leq 0 & \text { otherwise, }
\end{array}
$$

where $P_{\text {comb,max }}$ is the maximum power output of the combustion engine and $V_{\min }$ is the minimum volume of hydraulic fluid that must remain in the bladder accumulator. The latter is necessary to prevent the bladder from being damaged touching the outlet. These set the limits for gas volume and gas pressure, and ensure that the recuperation system's power input and output do not exceed the power necessary to decelerate the truck or the power that can be contributed by the combustion, respectively. This also allows that through increased power output to the cardan shaft, the combustion engine can simultaneously transfer energy to the recuperation system to be stored within the bladder accumulator, and accelerate the vehicle.

The optimization itself is carried out discretizing the variables $\gamma$ and $p_{1}$ in time, and using the obtained $\left\{\gamma^{i}\right\}$ and $\left\{p_{1}^{i}\right\}$ of the temporal nodes $i$ as independent variables. These variables are connected through the equations given in the previous sections as well as the constraints and objective function given above. A Newton interior-point algorithm with a logarithmic barrier function solves the constrained optimization as described in [54]. Additionally a large number of different randomly chosen starting points is used, which increases the probability of finding a global rather than a local minimum.

\section{Optimized Control}

The numerical results for the introduced endoreversible model are presented in this section. The obtained optimal solution is compared to a baseline strategy with regard to the dynamical behavior of the system and the resultant fuel savings. For the baseline strategy, we assume that the mechanical energy recuperation system supports the conventional power train in parallel, or even replaces the propulsion by the combustion engine as soon as possible.

For the initial state the pressure and temperature of the gas were chosen to be $p_{1}=p_{\max }$ and $T_{1}=50^{\circ} \mathrm{C}$ which roughly corresponds to a bladder accumulator that has just been fully charged. The velocity of the driving profile and resultant power to accelerate or decelerate the truck is shown in Figure 6. Here, $P_{\text {truck }}$ was calculated using Equation (22) and the height profile is constantly zero. 


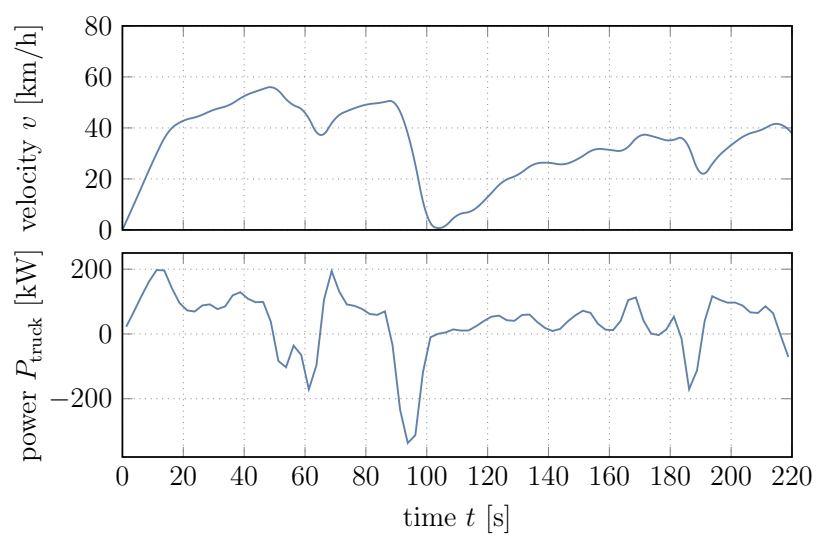

Figure 6. Velocity profile and corresponding power needed to accelerate or decelerate the truck.

On the left, in Figure 7 the key variables of the system with the baseline strategy are shown. At the top of the picture the displacement factor $\gamma$ can be seen, which varies almost only between its extreme values, so that propulsion can immediately be fully supported and the maximum amount of braking energy can be stored. The drive support always lasts until the gas pressure $p_{1}$ has reached its minimum value, as seen below, which corresponds to the minimum amount of hydraulic fluid within the accumulator, and hence an empty energy storage. Overall, the recuperation system is inactive over very long periods. Underneath, the resulting power distribution between the hydraulic unit and the internal combustion engine is shown, where, again, one can clearly see that the combustion engine is immediately supported as soon as there is energy stored within the bladder accumulator. At the bottom left of Figure 7 the efficiencies of the hydraulic unit $\eta_{\text {hyd }}$ and the combustion engine $\eta_{\text {comb }}$ can be seen. Particularly noteworthy here is that the efficiency of the hydraulic unit at low speeds reaches very low values as can bee seen at around $t=5 \mathrm{~s}$ and $t=110 \mathrm{~s}$.

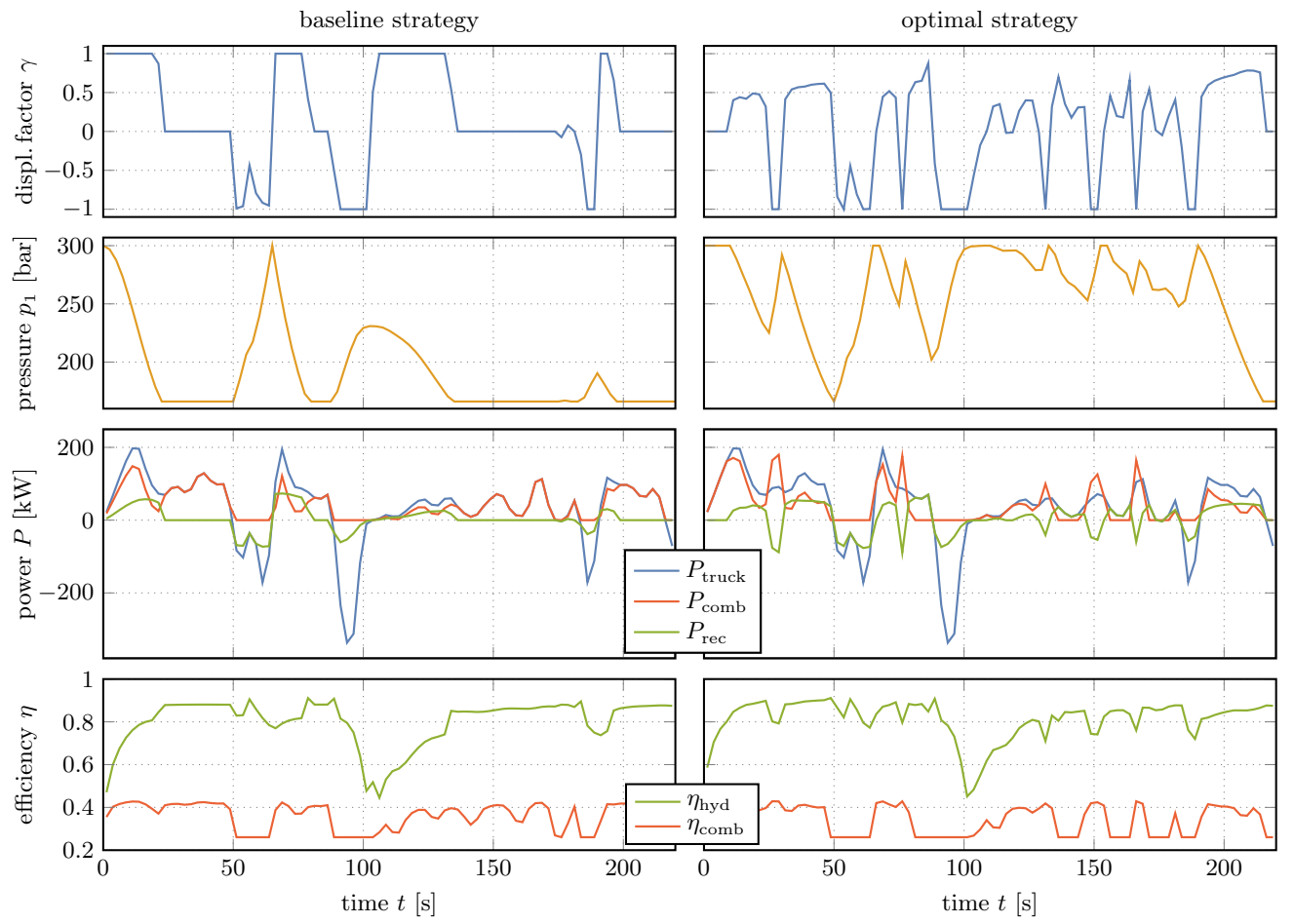

Figure 7. From top to bottom: displacement factor, gas pressure, power and efficiencies of hydraulic unit and combustion engine over time for (left) baseline strategy and (right) optimal strategy.

The resultant diesel fuel savings using the baseline strategy are $19.1 \%$. Having the baseline strategy as a reference we can now look at the optimized control strategies. 
The new feature in the optimized control strategy is that the engine can both propel the vehicle and transfer energy into the recuperation system at the same time. The results are shown on the right in Figure 7. Immediately apparent here is that the displacement factor does not switch only between its extreme values. While energy is still being stored with maximum available power, the displacement factor remains roughly between 0.3 and 0.8 during drive support. Furthermore, the recuperation is now active at almost all time. This leads to a higher mean pressure within the bladder accumulator resulting in higher energy recovering rates. We can now also see that the efficiencies improve slightly in several places and, in addition, up to $t=10 \mathrm{~s}$ the hydraulic unit no longer supports the propulsion since it can operate only with poor efficiency due to the low velocity of the truck and hence the low rotational speeds. On the other hand, while having high efficiency values at higher velocities e.g., at $t=140 \mathrm{~s}$ and $t=140 \mathrm{~s}$ the hydraulic unit supports or replaces the combustion engine which has low efficiency values there.

We can see that the possibility of simultaneous energy storing and propulsion is actually used, e.g., at $t=30 \mathrm{~s}$ and $t=150 \mathrm{~s}$. In these cases, the internal combustion engine operates with improved efficiency due to the increased power output. In addition, before and after, more energy from the recuperation system can be used in areas with high efficiency values of the hydraulic unit, which is particularly visible around $t=40 \mathrm{~s}$.

The fuel savings achieved with this optimal control strategy amount to $25.5 \%$ which equates to an improvement of more than one third compared to the baseline strategy.

Both strategies have in common that at $t=50 \mathrm{~s}$, the bladder accumulator is completely emptied which can be recognized by the minimum pressure value. The reason for this is that during the following braking process the bladder accumulator can be filled again and at $t=65 \mathrm{~s}$ the maximum pressure $p_{1}=p_{\max }$ is reached. Therefore, with the accumulator size used here, a split of the driving profile at this point and a separate optimization is possible as it is done, e.g., in [55]. However, for larger accumulator sizes it is easy to devise scenarios in which the stored energy should be saved for usage after a deceleration.

\section{Conclusions}

The modeling of the recuperation system presented in this work makes use of drastic coarsening, but proves its general feasibility. On the one hand, it might be adapted and used with realistic data for industrial purposes while on the other hand it serves as a basis for further investigations and model refinements. These refinements may include more pressure and heat losses as well as other possible sources for energy dissipation ans include them in the optimization. In addition, a heat exchange with the cooling circuit of the vehicle can be considered, and the components of the bladder accumulator can be described in more detail where different heat transfer processes depending on the current bladder size are conceivable.

On the basis of the shown optimizations as well as optimizations of future improved models, e.g., deterministic rules for a suitable fuel saving strategy could be derived and applied in order to make the daily traffic of commercial vehicles more environmentally friendly.

Author Contributions: Both authors contributed equally to this manuscript. All authors have read and agreed to the published version of the manuscript.

Funding: This research has been funded by the Bundesministerium für Wirtschaft und Energie under support code 19U15009C. The publication of this article was funded by Chemnitz University of Technology.

Conflicts of Interest: The authors declare no conflict of interest.

\section{References}

1. Pourmovahed, A.; Beachley, N.H.; Fronczak, F.J. Modeling of a Hydraulic Energy Regeneration System: Part I—Analytical Treatment. J. Dyn. Syst. Meas. Control 1992, 114, 155-159. [CrossRef] 
2. Moreno, J.; Ortúzar, M.E.; Dixon, J.W. Energy-Management System for a Hybrid Electric Vehicle, Using Ultracapacitors and Neural Networks. IEEE Trans. Ind. Electron. 2006, 53, 614-623. [CrossRef]

3. Sciarretta, A.; Guzzella, L. Control of hybrid electric vehicles. IEEE Contr. Syst. Mag. 2007, 27, 60-70.

4. Peng, D.; Zhang, Y.; Yin, C.L.; Zhang, J.W. Combined control of a regenerative braking and anti-lock braking system for hybrid electric vehicles. Int. J. Automot. Technol. 2008, 9, 749-757. [CrossRef]

5. Ahn, J.K.; Jung, K.H.; Kim, D.H.; Jin, H.B.; Kim, H.S.; Hwang, S.H. Analysis of a regenerative breaking system for hybrid electric vehicles using an electro-mechanical brake. Int. J. Automot. Thechnol. 2009, 10, 229-234. [CrossRef]

6. Hui, S.; Ji-hai, J.; Xin, W. Torque control strategy for a parallel hydraulic hybrid vehicle. J. Terramechanics 2009, 46, 259-265. [CrossRef]

7. Nejabatkhah, F.; Danyali, S.; Hosseini, S.H.; Sabahi, M.; Niapour, S.M. Modeling and Control of a New Three-Input DC-DC Boost Converter for Hybrid PV/FC/Battery Power System. IEEE Trans. Power Electron. 2012, 27, 2309-2324. [CrossRef]

8. Chen, Y.L.; Liu, S.A.; Jiang, J.H.; Shang, T.; Zhang, Y.K.; Wei, W. Dynamic analysis of energy storage unit of the hydraulic hybrid vehicle. Int. J. Automot. Thechnol. 2013, 14, 101-112. [CrossRef]

9. Wang, W.; Zhao, J. Energy-Efficient Robust Control for Direct Drive and Energy Recuperation Hydraulic Servo System. Complexity 2020, 6959273. [CrossRef]

10. Schwalbe, K.; Fischer, A.; Hoffmann, K.H.; Mehnert, J. Applied endoreversible thermodynamics: Optimization of powertrains. In Proceedings of the ECOS 2014-27th International Conference on Efficiency, Cost, Optimization, Simulation and Environmental Impact of Energy Systems, ECOS 2014, Turku, Finland, 15-19 June 2014; Zevenhouen, R., Ed.; Åbo Akademi University: Turku, Finland, 2014; 45-55.

11. Hoffmann, K.H.; Burzler, J.M.; Schubert, S. Endoreversible Thermodynamics. J. Non-Equilib. Thermodyn. 1997, $22,311-355$.

12. Salamon, P.; Nitzan, A.; Andresen, B.; Berry, R.S. Minimum Entropy Production and the Optimization of Heat Engines. Phys. Rev. A 1980, 21, 2115-2129. [CrossRef]

13. Rubin, M.H.; Andresen, B. Optimal Staging of Endoreversible Heat Engines. J. Appl. Phys. 1982, 53, 1-7. [CrossRef]

14. De Vos, A. Reflections on the power delivered by endoreversible engines. J. Phys. D Appl. Phys. 1987, 20, 232-236. [CrossRef]

15. Hoffmann, K.H.; Burzler, J.M.; Fischer, A.; Schaller, M.; Schubert, S. Optimal Process Paths for Endoreversible Systems. J. Non-Equilib. Thermodyn. 2003, 28, 233-268. [CrossRef]

16. Fischer, A.; Hoffmann, K.H. Can a quantitative simulation of an Otto engine be accurately rendered by a simple Novikov model with heat leak? J. Non-Equilib. Thermodyn. 2004, 29, 9-28. [CrossRef]

17. Huleihil, M.; Andresen, B. Optimal piston trajectories for adiabatic processes in the presence of friction. J. Appl. Phys. 2006, 100, 114914. [CrossRef]

18. Aragón-González, G.; Canales-Palma, A.; León-Galicia, A.; Morales-Gómez, J.R. Maximum Power, Ecological Function and Efficiency of an Irreversible Carnot Cycle. A Cost and Effectiveness Optimization. Braz. J. Phys. 2008, 38, 1-8. [CrossRef]

19. Wu, C. Maximum Obtainable Specific Cooling Load of a Refrigerator. Energ. Convers. Manag. 1995, 36, 7-10. [CrossRef]

20. Chen, J.; Andresen, B. The Maximum Coefficient of Performance of Thermoelectric Heat Pumps. Int. J. Power Energy Syst. 1996, 17, 22-28. [CrossRef]

21. Wagner, K.; Hoffmann, K.H. Endoreversible modeling of a PEM fuel cell. J. Non-Equilib. Thermodyn. 2015, 40, 283-294. [CrossRef]

22. Marsik, F.; Weigand, B.; Thomas, M.; Tucek, O.; Novotny, P. On the Efficiency of Electrochemical Devices from the Perspective of Endoreversible Thermodynamics. J. Non-Equilib. Thermodyn. 2019, 44, 425-437. [CrossRef]

23. Badescu, V. The Theoretical Maximum Efficiency of Solar Converters with and Without Concentration. Energy 1989, 14, 237-239. [CrossRef]

24. De Vos, A. Is a solar cell an edoreversible engine? Sol. Cells 1991, 31, 181-196. [CrossRef]

25. Schwalbe, K.; Hoffmann, K.H. Optimal Control of an Endoreversible Solar Power Plant. J. Non-Equilib. Thermodyn. 2018, 43, 255-271. [CrossRef]

26. Schwalbe, K.; Hoffmann, K.H. Stochastic Novikov engine with time dependent temperature fluctuations. Appl. Thermal Eng. 2018, 142, 483-488. [CrossRef]

27. Smith, Z.; Pal, P.S.; Deffner, S. Endoreversible Otto Engines at Maximal Power. J. Non-Equilib. Thermodyn. 2020, 45, 305-310. [CrossRef]

28. Gordon, J.M.; Orlov, V.N. Performance Characteristics of Endoreversible Chemical Engines. J. Appl. Phys. 1993, 74, 5303-5309. [CrossRef]

29. Wagner, K.; Hoffmann, K.H. Chemical reactions in endoreversible thermodynamics. Eur. J. Phys. 2016, 37, 015101. [CrossRef]

30. Gordon, J.M.; Zarmi, Y. Wind Energy a Solar-Driven Heat Engine: A Thermodynamic Aproach. Am. J. Phys. 1989, 57, 995-998. [CrossRef]

31. De Vos, A. Endoreversible Models for the Thermodynamics of Computing. Entropy 2020, 22, 660. [CrossRef]

32. Mozurkewich, M.; Berry, R.S. Optimal Paths for Thermodynamic Systems: The ideal Otto Cycle. J. Appl. Phys. 1982, 53, 34-42. [CrossRef]

33. Xia, S.; Chen, L.; Sun, F. Maximum power configuration for multireservoir chemical engines. J. Appl. Phys. 2009, 105, 1-6. [CrossRef]

34. Hoffmann, K.H.; Watowich, S.J.; Berry, R.S. Optimal Paths for Thermodynamic Systems: The Ideal Diesel Cycle. J. Appl. Phys. 1985, 58, 2125-2134. [CrossRef] 
35. Burzler, J.M.; Blaudeck, P.; Hoffmann, K.H. Optimal Piston Paths for Diesel Engines. In Thermodynamics of Energy Conversion and Transport; Stanislaw Sieniutycz, S., de Vos, A., Eds.; Springer: Berlin, Germany, 2000; pp. 173-198.

36. Lin, J.; Chang, S.; Xu, Z. Optimal motion trajectory for the four-stroke free-piston engine with irreversible Miller cycle via a Gauss pseudospectral method. J. Non-Equilib. Thermodyn. 2014, 39, 159-172. [CrossRef]

37. Kojima, S. Theoretical Evaluation of the Maximum Work of Free-Piston Engine Generators. J. Non-Equilib. Thermodyn. 2017, 42, 31-58. [CrossRef]

38. Tang, C.; Feng, H.; Chen, L.; Wang, W. Power density analysis and multi-objective optimization for a modified endoreversible simple closed Brayton cycle with one isothermal heating process. Energy Rep. 2020, 6, 1648-1657. [CrossRef]

39. Kojima, S. Maximum Work of Free-Piston Stirling Engine Generators. J. Non-Equilib. Thermodyn. 2017, 42, 169-186. [CrossRef]

40. Watowich, S.J.; Hoffmann, K.H.; Berry, R.S. Intrinsically Irreversible Light-Driven Engine. J. Appl. Phys. 1985, 58, $2893-2901$. [CrossRef]

41. Watowich, S.J.; Hoffmann, K.H.; Berry, R.S. Optimal Paths for a Bimolecular, Light-Driven Engine. Il Nuovo Cim. B 1989, 104, 131-147. [CrossRef]

42. Ma, K.; Chen, L.; Sun, F. Optimal paths for a light-driven engine with a linear phenomenological heat transfer law. Sci. China Chem. 2010, 53, 917-926. [CrossRef]

43. Gonzalez-Ayala, J.; Mateos Roco, J.M.; Medina, A.; Calvo Hernández, A. Optimization, Stability, and Entropy in Endoreversible Heat Engines. Entropy 2020, 22, 1323. [CrossRef] [PubMed]

44. Schwalbe, K.; Hoffmann, K.H. Novikov engine with fluctuating heat bath temperature. J. Non-Equilib. Thermodyn. 2018, 43, 141-150. [CrossRef]

45. Schwalbe, K.; Hoffmann, K.H. Performance Features of a Stationary Stochastic Novikov Engine. Entropy 2018, 20, 52. [CrossRef]

46. Schwalbe, K.; Hoffmann, K.H. Stochastic Novikov Engine with Fourier Heat Transport. J. Non-Equilib. Thermodyn. 2019, 44, 417-424. [CrossRef]

47. Wu, B.; Lin, C.C.; Filipi, Z.; Peng, H.; Assanis, D. Optimization of power management strategies for a hydraulic hybrid medium truck. In Proceedings of the 6th International Symposium on Advanced Vehicle Control, Hiroshima, Japan, 9-13 September 2002.

48. Hui, S.; Junqing, J. Research on the system configuration and energy control strategy for parallel hydraulic hybrid loader. Automat. Constr. 2010, 19, 213-220. [CrossRef]

49. Filipi, Z.; Kim, Y.J. Hydraulic Hybrid Propulsion for Heavy Vehicles: Combining the Simulation and Engine-In-the-Loop Techniques to Maximize the Fuel Economy and Emission Benefits. Oil Gas Sci. Technol. 2010, 65, 155-178. [CrossRef]

50. Masser, R.; Hoffmann, K.H. Endoreversible Modeling of a Hydraulic Recuperation System. Entropy 2020, 22, 383. [CrossRef]

51. Muschik, W.; Hoffmann, K.H. Endoreversible Thermodynamics: A Tool for Simulating and Comparing Processes of Discrete Systems. J. Non-Equilib. Thermodyn. 2006, 31, 293-317. [CrossRef]

52. Masser, R.; Hoffmann, K.H. Dissipative Endoreversible Engine with Given Efficiency. Entropy 2019, 21, 1117. [CrossRef]

53. Muschik, W.; Hoffmann, K.H. Modeling, Simulation, and Reconstruction of 2-Reservoir Heat-to-Power Processes in Finite-Time Thermodynamics. Entropy 2020, 22, 997. [CrossRef]

54. El-Bakry, A.S.; Tapia, R.A.; Tsuchiya, T.; Zhang, Y. On the Formulation and Theory of the Newton Interior-Point Method for Nonlinear Programming. J. Optim. Theory Appl. 1996, 89, 507-541. [CrossRef]

55. Bender, F.A.; Kaszynski, M.; Sawodny, O. Drive Cycle Prediction and Energy Management Optimization for Hybrid Hydraulic Vehicles. IEEE Trans. Veh. Technol. 2013, 62, 3581-3592. [CrossRef] 